\title{
POLISH SECTION
}

In the Nos. 5-6, vol. VI/1948/ of $\mathrm{S}$ y $\mathrm{n}$ the $\mathrm{s}$ e we published as a Polish Section a summary of an article by our Polish editor, Dr. Mieczyslaw Choynowski, President of the Circle for the Science of Science in Cracow, and a note about the aims and activities of this Circle, which both appeared about two years ago in its monthly organ $\mathrm{Zyc}$ ie $\mathrm{Nauki}$ (Life of S o i a c e).

We want to point out that we have published this article, by way of introduction, under our own responsibility.

Dr. Choynowski hopes that the first appearance of his section under $h$ is editorship will represent the Polish contemporary philosophic and scientific thought somewhat better than a short summary of his article which we have published and which, even in its unabridged form, would be rather out of place - without additional comments - in sy $\mathrm{n}$ the se, being the ideological discussion of the editor of $\mathrm{L}$ if e of $\mathrm{Sci}$ ence with some representatives of different attitudes. He informs us at the same time that he has started to secure collaboration of leading Polish authors in the field of scientific philosophy, logic and theory of language, such as K. Ajdukiewicz, S. Jaskowski, M. Kokoszynska-Lutmanowa, T. Kotarbinski, H. Mehlberg, M. Ossowska, S. Ossowski, A. Tarski, W. Tatarkiewicz, Z. Zawirski (who died in the meantime, on April 2nd 1948), C. Znamierowski, and others, whose names are not yet known abroad.

The address of the Circle for the Science of Science and of $\mathrm{L}$ if $\mathrm{e}$ of Scie n ce has changed and is now: Slowackiego 66, Cracow 1, Poland. 